\title{
ANALISIS BAURAN PEMASARAN DI HOTEL PANGERAN BEACH PADANG
}

\author{
Nurmala Widyastuti' ${ }^{1}$ Youmil Abrian ${ }^{2}$ \\ Program Studi D4 Manajemen Perhotelan \\ Fakultas Pariwisata dan Perhotelan \\ Universitas Negeri Padang \\ email: malla.ichat.mi@gmail.com
}

\begin{abstract}
Based on this study to analyze the marketing mix at the Pangeran Beach Hotel Padang. This type of research is a qualitative descripptive. Determination of informants using purposive sampling technique that is many as eight research informants consisting of hotel marketing and hotel consumers. The results obtained from this study are as follows : 1) The products offered by the Pangeran Beach Hotel Padang are quality attractive and of high quality and the service provide to guests are good, 2) The Price set by the Pangeran Beach Hotel Padang is quite high and is only affordable for middle and upper class people, 3) Promotions carried out by the Pangeran Beach Hotel Padang have been maximized so that guests are still intererted in staying at the hotel, 4) The Place or location of the Pangeran Beach Hotel Padang is already strategic annd in the city center, and works together to travel agents so that guests know the location of the Pangeran Beach Hotel Padang.
\end{abstract}

\section{Keywords : Marketing, Marketing mix}

\section{PENDAHULUAN}

Industri perhotelan pada saat ini merupakan salah satu aspek yang mempunyai peranan penting dalam perkembangan pariwisata di Kota Padang, yang menyediakan jasa akomodasi bagi para wisatawan. Jumlah kunjungan wisatawan yang mengalami peningkatan berpengaruh pada perkembangan industri perhotelan karena dengan meningkatnya jumlah kunjungan wisatawan akan meningkatkan pula kebutuhan akan jasa akomodasi khususnya industri perhotelan. Pesatnya pertumbuhan bisnis perhotelan mengakibatkan tingkat persaingan antar hotel yang tinggi. Namun bagi sejumlah hotel, kondisi tersebut tidak menjadi kekhawatiran besar sepanjang target pasar yang masih tersedia. Para pengelola hotel harus berusaha sebaik mungkin dalam memanfaatkan pasar yang ada dengan memberi citra dan layanan khusus bagi para tamunya.

Hotel merupakan salah satu bisnis di bidang jasa yang mana berupa bangunan yang memiliki beberapa ruangan, fasilitas maupun layanan yang disewakan untuk beristirahat ataupun berbisnis. Menurut Rumekso (2001: 2), "Hotel adalah bentuk bangunan yang menyediakan kamar-kamar untuk menginap para tamu, makanan dan minuman, serta fasilitas-fasilitas yang diperlukan, dan dikelola secara profesional untuk mendapatkan keuntungan (profit)". Menurut Al Bataafi (2006: 11), "Berdasarkan 
fasilitas dan pernyataannya, hotel dapat digolongkan menjadi tingkatan yaitu, hotel bintang satu (*), hotel bintang dua $(* *)$, hotel bintang tiga $(* * *)$, hotel bintang empat (****), dan hotel bintang lima (*****). Hotel Pangeran Beach Padang merupakan salah satu hotel berbintang empat (****) pertama yang berdiri di Kota Padang, tergolong hotel yang memiliki fasilitas lengkap dan mewah. Bangunan besar dan tinggi hotel ini didesain dengan baik, rapi serta kokoh. Hotel ini menjadi landmark yang menandai kawasan Kota Padang. Selain itu Hotel Pangeran Beach Padang juga menampilkan desain bangunan bergaya modern yang memenuhi kebutuhan akomodasi di kawasan bisnis dan wisata di Kota Padang. Lokasi yang strategis dan berada di puast kota serta akses menuju ke hotel yang sangat mudah menjadi daya tarik sendiri bagi tamu untuk menginap di hotel ini. Hotel Pangeran Beach Padang berada di Jl. Ir. H. Juanda No. 79 Kota Padang dengan jumlah kamar 179 kamar berserta fasiliasnya. Hotel Pangeran Beach Padang di dalam mempertahankan produk beserta jasanya tersebut harus berusaha melakukan strategi marketing yang tepat.

Dalam rangka pencapaian tujuan perusahaan memerlukan suatu usaha yaitu penyusunan strategi, di dalam menyusun suatu strategi yang sesuai merupakan salah satu aspek untuk menentukan keberhasilan perusahaan di dalam menciptakan visi serta misinya, tidak terkecuali dengan Hotel Pangeran Beach Padang yang merupakan suatu perusahaan yang menyediakan jasa penginapan, dengan tujuan menjuarai persaingan di dalam memasarkan produk maupun jasa. Adapun visi dan misi dari Hotel Pangeran Beach Padang sendiri yaitu menjadi leader hotel di Kota Padang dengan menonjolkan Streng Point yaitu satu satunya hotel berbintang karena berada dipinggir pantai, sedangkan misi dari Hotel Pangeran Beach Padang yaitu menciptakan akomodasi penginapan dan ruang meeting dengan semua sarana dan prasana pendukung lainnya untuk mencapai kepuasan pelanggan.

Menurut Assauri (2009:167), "Setiap perusahaan mempunyai tujuan untuk tetap hidup dan berkembang, tujuan tersebut hanya dapat dicapai melalui usaha mempertahankan dan meningkatkan tingkat keuntungan/laba perusahaan". Suatu usaha bisa dilakukan bilamana perusahaan bisa mempertahankan serta meningkatkan keuntungan/laba perusahaan, dengan cara meningkatkan penjualanya melalui usaha mencari langganan, dan menguasi pasar. Tujuan tersebut bisa dicapai bilamana departemen marketing perusahaan melaksanakan strategi yang pas untuk dapat menggunakan peluang yang ada di dalam pemasaran, sehingga posisi sebuah perusahaan di pasar bisa dipertahankan dan ditingkatkan.

Berbagai hotel akan berlombalomba untuk meningkatkan fasilitas dan pelayanan yang ada untuk bersaing dengan hotel lainnya, yang membedakan antara hotel yang satu denga yang lain diantaranya pada produk, harga, promosi, lokasi. Setiap 
hotel pasti memberikan suatu nilai tambah yang berbeda terhadap produk serta jasa dan pelayanan yang diberikan kepada tamu. Nilai tambah tersebut membuat suatu penginapan berbeda dari penginapan pada umumnya, yang berakibat mengapa orang punya alasan tersendiri untuk memilih penginapan itu dibanding dengan penginapan lain. Untuk mencapai hasil maksimal diperlukan adanya strategi pemasaran agar menarik tamu untuk menginap di penginapan tersebut. Ada empat elemen yang digunakan untuk menganalisis teknik bauran pemasaran antara lain produk, harga, promosi, lokasi. Berdasarkan dari tinjauan latar belakang di atas, maka peneliti memiliki keinginan untuk mengetahui bauran pemasaran apa yang dipakai oleh Hotel Pangeran Beach Padang dengan judul Analisis Bauran PemasaranDi Hotel Pangeran Beach Padang.

\section{LANDASAN TEORI}

1. Pengertian Pemasaran Pemasaran adalah sebagai kegiatan yang direncanakan dan diorganisasikan yang meliputi pendistribusian barang, penetapan harga dan dilakukan pengawasan terhadap kebijakan - kebijakan yang telah dibuat yang tujuannya untuk mendapatkan tempat dipasar agar tujuan utama dari pemasaran dapat tercapai. Menurut Kotler dalam Subroto (2011:1),

"Pemasaran sebagai suatu proses sosial dimana setiap individu dan kelompok mendapatkan apa yang mereka butuhkan dan inginkan dengan menciptakan dan mempertukarkan produk dan nilai dengan individu atau kelompok lainnya".
2. Bauran Pemasaran

a. Pengertian Bauran Pemasaran

Bauran pemasaran adalah segala sesuatu yang dapat perusahaan lakukan untuk mempengaruhi permintaan atas produknya. Menurut Kotler (2009: 24), bauran pemasaran adalah,

"Serangkaian alat pemasaran taktis yang dapat di kendalikan produk, harga, tempat, dan promosi yang di padukan oleh perusahaan untuk mengahasilkan tanggapan yang diinginkan perusahaan dalam pasar sasaran".

b. Unsur-Unsur Bauran Pemasaran

Unsur - unsur bauran pemasaran menurut Kotler dan Keller (2009: 24), terdiri atas 4P yaitu produk (product), harga (price), promosi (promotion), dan tempat (place).

\section{METODOLOGI PENELITIAN}

Jenis penelitian ini adalah penelitian deskriptif kualitatif dengan menggunakan metode survei. Penelitian deskriptif merupakan penelitian yang bertujuan untuk mengetahui nilai variable mandiri, baik hanya pada satu variable atau lebih (variabel yang berdiri sendiri) dimana penelitian tidak membuat perbandingan variabel itu pada sampel yang lain dan mencari hubungan variabel itudengan variabel lain.

Penelitian kualitatif tidak menggunakan populasi. Sampel dalam 
penelitian kualitatif dinamakan sebagai informan. Penentuan informan yang akan diwawancarai dilakukan dengan teknik purposive yaitu teknik penentuan informan dengan pertimbangan dan tujuan tertentu sesuai yang dibutuhkan.

Dalam penelitian ini yang akan dijadikan informan adalah Marketing Manager, Marketing Staff, dan ditambahkan dengan data pendukung dari beberapa pihak (konsumen) Hotel Pangeran Beach Padang yaitu empat konsumen.

Teknik pengumpulan data yang digunakan adalah observasi, wawancara serta dokumentasi. Teknik analisis data model interaktif meliputi tiga jalur kegiatan yaitu: reduksi data, penyajian data serta pengambilan kesimpulan.

\section{GAMBARAN OBJEK PENELITIAN}

Hotel Pangeran Beach Padang yang beralamat di jalan Ir. Juanda No 79 Padang merupakan hotel kedua yang dibangun oleh bapak Sy.Dt.Pangeran setelah Hotel Pangeran City yang beralamat di jalan dobi No 3-5 Padang. Hotel Pangeran Beach Padang oleh PT Istano Pangeran adalah perluasan dari Hotel Pangeran City yang didirikan pada tanggal 17 april 1979. Dengan didirikannya Hotel Pangeran Beach Padang yang baru pada tanggal 21 Desember 1989 di jalan Ir. Juanda No 79 Padang, di harapkan dapat teretasinya suatu masalah yaitu kekurangan jumlah kamar yang selama ini terjadi, hingga tidak banyak lagi tamu kelompok (grup) di tolak. Penolakan ini adalah untuk menghindari kondisi full house, karean di perlukan reserved room untuk para pelanggan tetap.

Hotel Pangeran Beach Padang mulai beroperasi dengan kondisi kamar 65 siap huni. Pada tanggal 7 juli 1991 jumlah kamar tersedia 105 kamar, sedangkan untul full operation jumlah kamar akan mencapi 139 kamar. Seiring dengan perkembangan dunia pariwisata dan kebutuhan akan kamar hotel, maka pada tahun 2006 diadakanlah penambahan kamar sehingga menjadi 176 kamar yang dibuat dengan penambahan bangunan satu tingkat ke lantai VI. Dengan penambahan kamar dan fasilitas pendukung lainnya, maka lengkaplah Hotel Pangeran Beach masuk kriteria Klasifikasi Hotel Berbintang Empat yang resmi dikeluarkan oleh PHRI pada bulan Mei 2007. Pangeran Beach Hotel merupakan hotel berbintang tiga pertama di Kota Padang. Hotel ini mulai beropersi pada tanggal 30 Desember 1989 dan terus melakukan pembenahan dan inovasi yang bertujuan untuk meningkatkan kualitas pelayanan di bidang jasa perhotelan.

\section{HASIL PENELITIAN}

\section{Produk}

Hotel Pangeran Beach Padang di dalam menawarkan produk kepada tamu nya sudah memiliki variasi produk yang cukup menarik untuk tamu agar tetap menginap di hotel, selanjutnya kualitas produk yang di tawarkan oleh Hotel Pangeran Beach Padang kepada tamu hotel nya yaitu telah memiliki kualitas yang baik, itu di lihat dari hal utama apabila produk itu di katakan 
berkualitas, yaitu (ketahanan, kehandalan, kemudahan, perbaikan, dan gaya) dan itu juga sesuai dengan kualifikasi hotel bintang 4 yang di miliki oleh Hotel Pangeran Beach Padang. Selanjutnya pelayanan merupakan unsur terpenting, pihak Hotel Pangeran Beach Padang memberikan pelayanan kepada tamunya sudah bagus itu dilihat dari karyawan hotel yang murah senyum kepada tamunya, komunikasi yang baik, dan perlakuan ramah dan lembut terhadap semua tamunya. Kemudian pemberian garansi kepada tamunya yang dilakukan oleh Hotel Pangeran BeachPadang itu bertujuan untuk meyakinkan konsumen bahwa produk dalam keadaan baik atau bebas dari kerusakan akibat dari ketidaktelitian pengerjaan atau penggunaan material yang kurang baik dan berlaku untuk jangka waktu tertentu, hal ini sesuai dengan apabila ada masalah di dalam kamar tamu maka hotel akan segera mencari kamar yang sesuai dengan tipe yang sama dan dengan kualitas yang lebih baik

\section{Harga}

Harga dasar yang di tawarkan oleh Hotel Pangeran Beach Padang kepada tamu nya cukup tinggi dan itu hanya terjangkau untuk kalangan menengah keatas, dan itu dapat di lihat dari harga untuk tipe kamar standar sudah tinggi. Selanjutnya potongan harga yang diberikan oleh Hotel Pangeran Beach Padang kepada tamu atau konsumen tertentu serta harga yang di berikan bersifat fleksibel dan dapat di negosiasi serta tawar menawar maka timbul persetujuan. Selanjutnya untuk jangka waktu pembayaran Hotel Pangeran Beach Padang telah memiliki aturan nya, jangka waktu pembayaran hanya berlaku untuk kamu yang bersifat goverment, tidak untuk tamu individu.

\section{Promosi}

Hotel Pangeran Beach Padang dalam membuat iklan yaitu bekerja dengan radio yang berada di kota padang serta memasarkan hotelnya melalui koran lokal yang berada di Kota Padang. Selanjutnya promosi penjualan yang dilakukan oleh Hotel Pangeran Beach Padang yaitu dengan cara salah satunya yaitu door to door. Personal selling yang dilakukan oleh Hotel Pangeran Beach Padang dilakukan setiap hari yang melibatkan interaksi personal langsung antara pembeli potensial dengan marketing hotel. Hubungan masrayakat yang dilakukan oleh Hotel Pangeran Beach Padang melalui pendekatan kepada masyarakat dan berusaha menarik minat masyarakat agar berminat untuk menginap di Hotel Pangeran Beach Padang. Selanjutnya pemasaran langsung yang dilakukan oleh Hotel Pangeran Beach Padang yaitu dengan turunnya langsung kelapangan atau instansi dengan menurunkan staff marketing yang berbeda beda setiap harinya.

\section{Tempat}

Aksesibilitas atau untuk menuju Hotel Pangeran Beach Padang ini cukup mudah terjangkau dikarenakan hotel yang berlokasi di pusat kota dan strategis. Selanjutnya saluran disribusi yang di gunakan oleh Hotel Pangeran Beach Padang yaitu bekerja sama dengan beberapa travel agent online dan 
travel agent lain nya yang berada di Sumatera Barat, dan itu mempermudah tamu untuk melakukan pemesanan kamar apabila tamu tersebut berasal dari luar kota. Cakupan pasar yang dimiliki oleh Hotel Pangeran Beach Padang ini sudah cukup luas bahkan sampai ke tingkat nasional contoh nya seperti daerah khusus ibu kota jakarta, dan daerah Sumatera Barat pun sudah menjadi cakupan pasar yang dimiliki dari Hotel Pangeran Beach Padang ini. Transportasi untuk menuju Hotel Pangeran Beach Padang ini sangatlah mudah, berbagai macam tansportasi bisa di pilih baik dari umum maupun pribadi ini di karenakan lokasi dari Hotel Pangeran Beach Padang ini yang strategis dan berada di pusat kota.

\section{PEMBAHASAN}

Berdasarkan hasil observasi dan wawancara peneliti dengan marketing manager, marketing staff dan konsumen Hotel Pangeran Beach Padang, dapat disimpulkan bahwa unsur-unsur bauran pemasaran terdiri atas 4P yaitu produk (product), harga (price), promosi (promotion), dan tempat (place) sebagai berikut :

\section{Produk}

Hotel Pangeran Beach Padang di dalam menawarkan produk kepada tamu nya sudah memiliki variasi produk yang cukup menarik untuk tamu agar tetap menginap di hotel, selanjutnya kualitas produk yang di tawarkan oleh Hotel Pangeran Beach Padang kepada tamu hotel nya yaitu telah memiliki kualitas yang baik, itu di lihat dari hal utama apabila produk itu di katakan

\section{berkualitas, yaitu (ketahanan,} kehandalan, kemudahan, perbaikan, dan gaya) dan itu juga sesuai dengan kualifikasi hotel bintang 4 yang di miliki oleh Hotel Pangeran Beach Padang. Selanjutnya pelayanan merupakan unsur terpenting, pihak Hotel Pangeran Beach Padang memberikan pelayanan kepada tamunya sudah bagus itu dilihat dari karyawan hotel yang murah senyum kepada tamunya, komunikasi yang baik, dan ramah terhadap tamunya. Kemudian pemberian garansi kepada tamunya yang dilakukan oleh Hotel Pangeran Beach Padang itu bertujuan untuk meyakinkan konsumen bahwa produk yang di tawarkan dalam keadaan baik, hal ini sesuai dengan apabila ada masalah di dalam kamar tamu maka hotel akan segera mencari kamar yang sesuai dengan tipe yang sama dan dengan kualitas yang lebih baik.

Dengan begitu bisa diketahui maka produk yang ditawarkan oleh Hotel Pangeran Beach Padang mencakup beberapa unsur yakni kamar sebagai produk inti yang di tawarkan terhadap tamu hotel sehingga dapat memuaskan keinginan/kebutuhan konsumen dan produk lainnya yang mendukung kebutuhan konsumen. Sebagaimna yang dijelaskan oleh Kotler dan Amstrong (2008 : 266), bahwa Produk bisa didefinisikan sebagai segala sesuatu yang dapat ditawarkan ke pasar untuk mendapatkan perhatian, dibeli, dipergunakan, atau dikonsumsi dan dapat memuasakan keinginan / kebutuhan.

2. Harga 
Harga yang di tawarkan oleh Hotel Pangeran Beach Padang memiliki beberapa unsur yaitu terdiri dari harga dasar, harga dasar yang di tawarkan oleh Hotel Pangeran Beach Padang kepada tamu nya cukup tinggi dan itu hanya terjangkau untuk kalangan menengah keatas, dan itu dapat di lihat dari harga untuk tipe kamar standar sudah tinggi. Selanjutnya potongan harga yang diberikan oleh Hotel Pangeran Beach Padang kepada tamu atau konsumen tertentu serta harga yang di berikan bersifat fleksibel dan terjadi negosiasi atau tawar menawar maka timbul kata sepakat. Selanjutnya untuk jangka waktu pembayaran Hotel Pangeran Beach Padang telah memiliki aturan nya, jangka waktu pembayaran hanya berlaku untuk kamu yang bersifat goverment, tidak untuk tamu individu.

Dengan begitu bisa di ketahui harga yang di tawarkan oleh Hotel Pangeran Beach Padang hanya bisa terjangkau untuk kalangan menengah ke atas, dan harga di difinisikan sebagai apa yang diserahkan atau di korbankan oleh konsumen untuk memperoleh produk serta jasa. Sebagaimana yang dijelaskan oleh Kotler dan Amstrong (2008 : 345) harga adalah, "sejumlah uang yang ditagihkan untuk suatu produk barang atau jasa, atau jumlah dari nilai yang ditukarkan para pelanggan untuk memperoleh manfaat dari memiliki atau menggunakan suatu produk atau jasa.

\section{Promosi}

Jenis promosi yang di lakukan oleh Hotel Pangeran Beach Padang yaitu salah satu nya melalui periklanan,
Hotel Pangeran Beach Padang dalam membuat iklan yaitu bekerja dengan radio yang berada di kota padang serta memasarkan hotelnya melalui koran lokal yang berada di Kota Padang. Selanjutnya promosi penjualan yang dilakukan oleh Hotel Pangeran Beach Padang yaitu dengan cara salah satunya yaitu door to door. Personal selling yang dilakukan oleh Hotel Pangeran Beach Padang dilakukan setiap hari dengan melibatkan interaksi langsung antara pembeli dengan marketing hotel. Hubungan masrayakat yang dilakukan oleh Hotel Pangeran Beach Padang melalui pendekatan kepada masyarakat dan berusaha menarik minat masyarakat agar berminat untuk menginap di Hotel Pangeran Beach Padang. Selanjutnya pemasaran langsung yang dilakukan oleh Hotel Pangeran Beach Padang yaitu dengan turunnya langsung kelapangan atau instansi dengan menurunkan staff marketing yang berbeda beda setiap harinya.

Dengan begitu bisa di simpulkan bahwa secara garis besar promosi yang di lakukakan oleh Hotel Pangeran Beach Padang tidak jauh terpaut dengan apa dilakukan oleh hotel-hotel yang memakai bauran promosi sebagai media komunikasinya, tapi jika di lihat lebih lanjut mereka melakukan promosi hampir setiap hari untuk penugasan kelapangan dengan staff yang berbeda beda setiap hari nya. Sebagaimana dijelaskan oleh Swee Hoon dkk (2000:12) pelaksanaan promosi melibatkan beberapa tahap salah satunya mengukur efektifitas. Pengukuran efektifitas ini sangat 
penting bagi perusahaan. Setiap alat promosi mempunyai pengukuran yang berbeda beda, tanpa dilakukannya pengukuran efektifitas tersebut maka sulit diketahui apakah tujuan dari perusahaan sudah tercapai atau belum.

\section{Tempat}

Faktor yang mempengaruhi tempat diantaranya adalah aksesibilitas, aksesibilitas atau untuk menuju Hotel Pangeran Beach Padang ini cukup mudah terjangkau dikarenakan hotel yang berlokasi di pusat kota dan strategis. Selanjutnya saluran disribusi yang di gunakan oleh hotel pangeran beach padang yaitu bekerja sama dengan beberapa travel agent online dan travel agent lain nya yang berada di Sumatera Barat, dan itu mempermudah tamu untuk melakukan pemesanan kamar apabila tamu tersebut berasal dari luar kota. Cakupan pasar yang dimiliki oleh hotel pangeran beach padang ini sudah cukup luas bahkan sampai ke tingkat nasional contoh nya seperti daerah khusus ibu kota jakarta, dan daerah sumatera barat pun sudah menjadi cakupan pasar yang dimiliki dari Hotel Pangeran Beach Padang ini. Transportasi untuk menuju Hotel Pangeran Beach Padang ini sangatlah mudah, berbagai macam tansportasi bisa di pilih baik dari umum maupun pribadi ini di karenakan lokasi dari Hotel Pangeran Beach Padang ini yang strategis dan berada di pusat kota.

Dengan begitu dapat di simpulkan bahwa strategi distribusi dan lokasi yang digunakan oleh Hotel Pangeran Beach Padang yaitu letaknya yang berada di pusat kota dan lokasi yang strategis dan banyak bekerja sama dengan travel agent agar tamu yang berasal dari luar kota mengetahui bahwasannya ada hotel yang berada di pusak kota dan akses menuju ke Hotel Pangeran Beach Padang pun mudah untuk di capai dengan bermacammacam alat transportasi. Sebagaimana dijelaskan oleh Tjiptono (2008:185), "Pendistribusian bisa diartikan sebagai kegiatan pemasaran yang berusaha memperlancar dan mempermudah penyampaian barang dan jasa produsen kepada konsumen, sehingga penggunaanya sesuai dengan yang di perlukan jenis, jumlah, harga, tempat, dan saat dibutuhkan.

\section{SIMPULAN DAN SARAN}

1. Simpulan

Berdasarkan hasil penelitian yang didapatkan dari observasi, wawancara, serta dokumentasi, maka dapat diambil kesimpulan mengenai analisis bauran pemasaran di Hotel Pangeran Beach Padang sebagai berikut:

a. Produk

Produk yang ditawarkan oleh Hotel Pangeran Beach Padang yaitu kamar hotel sebagai produk inti yang di tawarkan kepada tamu hotel sehingga dapat memuaskan keinginan/kebutuhan konsumen dan produk lainnya yang mendukung kebutuhan konsumen.

b. Harga

Harga yang di tawarkan oleh Hotel Pangeran Beach Padang 
hanya bisa terjangkau untuk

kalangan menengah ke atas.

c. Promosi

Promosi yang di lakukakan oleh Hotel Pangeran Beach Padang tidak jauh terpaut dengan apa dilakukan oleh hotel-hotel yang menggunakan bauran promosi sebagai media komunikasi nya, tapi dapat di lihat lebih lanjut mereka melakakukan promosi hampir setiap hari untuk penugasan kelapangan dengan staff yang berbeda beda setiap hari nya.

d. Saluran distribusi dan lokasi

Saluran Distribusi dan Lokasi yang digunakan oleh Hotel Pangeran Beach Padang yaitu letaknya yang berada di pusat kota dan lokasi yang strategis dan banyak bekerja sama dengan travel agent agar tamu yang berasal dari luar kota mengetahui bahwasannya ada hotel yang berada di pusak kota dan akses menuju ke Hotel Pangeran Beach Padang pun mudah untuk di capai dengan bermacam-macam alat transportasi.

2. Saran

a. Bagi Hotel Pangeran Beach Padang hasil peneitian ini diharapkan dapat menjadi masukan serta mempertahankan strategi pemasarannya agar tetap unggul dengan banyak nya pertumbuhan hotel yang berada di Kota Padang, dan dapat juga mengevaluasi ulang strategi apakah yang cocok pada saat itu untuk tetap menarik minat tamu agar tetap menginap di hotel tersebut.

b. Bagi peneliti selanjutnya yang hendak mengembangkan penelitian ini dapat meneliti tentang unsur 7P bauran pemasaran yang ada di Hotel Pangeran Beach Padang.

c. Bagi jurusan Pariwisata khususnya mahasiswa D4 Manajemen Perhotelan dapat menjadikan penelitian ini sebagai bahan reverensi guna melakukan penelitian lebih lanjut.

\section{DAFTAR PUSTAKA}

Assauri, S. 2009. Manajemen Pemasaran,Dasar konsep dan Strategi.

Jakarta : Rajawali Pers

Kotler, Philip dan Gary Amstrong. 2008. Prinsip-prinsip Pemasaran. Edisi 12, Jilid 1. Jakarta : Erlangga . dan Keller, K. 2009. Manajemen Pemasaran, edisi Milenium, Jilid 1. Edisi Kedua Belas. Indeks. Jakarta

Tjiptono, Fandly. 2008. Strategi Pemasaran, edisi 3. Yogyakarta : ANDI 
